\title{
Establishing authorial presence by the exclusive-we: a functional approach to self-mentions in engineering research articles
}

\author{
Ayça SOLSUN \\ Postgraduate Student, English Language Teaching, Erciyes University, Kayseri, Turkey \\ Teacher of English, Ministry of National Education, Sivas, Turkey \\ https://orcid.org/0000-0002-5056-2509
}

Erdem AKBAŞ*

English Language Teaching, Erciyes University, Kayseri, Turkey https://orcid.org/0000-0003-2204-3119

\begin{tabular}{l}
\hline Article history \\
\hline Received: \\
29.04 .2021 \\
Received in revised form: \\
18.11 .2021 \\
Accepted: \\
08.12 .2021 \\
Key words: \\
\hline Authorial presence, academic \\
writing, interaction, self- \\
mentions, metadiscourse
\end{tabular}

Although academic writing has been seen as an objective form of writing, recent studies have shown that it is a form of social interaction and not totally impersonal. In line with this view, Hyland (2002) stated that academic writing is also strongly linked with the manifestation of authorial presence across the text. Included in the interactional metadiscourse framework devised by Hyland (2005), self-mentions enable writers to express their beliefs, show attitudes, become a part of the community, and interact with their readers. Consequently, academic texts become more credible, accountable, and interactive by the manifestation of authorial presence through self-mentions. This paper analyses the use, distribution and discourse functions of self-mentions, the we-oriented authorial presence in particular. The corpus of the study consisted of 200 Results and Discussion sections from research articles (RAs) published in the field of engineering and technology, totaling approximately 270,000 words. Both manual and automatic analyses were employed to achieve more accurate results and the verbs most frequently collocated with an explicit authorial we presence were also analysed manually. The results of the quantitative and qualitative analyses clearly showed that the most frequent function used in Results and Discussion sections in the field was explaining a procedure with 723 instances (54.69\%), and that the least frequent functions which writers employed were describing themselves and making a claim/prediction, each with two instances $(0.15 \%)$. The qualitative analysis showed that writers employed authorial presence to achieve different discourse functions (such as explaining a procedure, stating goals, describing themselves and making a claim or prediction), but preferred to avoid using more argumentative and interactional functions (describing themselves and making a claim or prediction), which can be strongly associated with the purpose of evading interaction with the readers.

\footnotetext{
*Correspondency: erdemakbas@erciyes.edu.tr
} 


\section{Introduction}

Until recently, academic writing was perceived as a chiefly unbiased reflection of neutral and accurate facts (Hyland, 2001). If researchers manage to avoid bias and be impartial, it is highly possible to state that researchers and authors believe that readers can easily interpret the information or message which authors imply, and discover the equal reality presented by researchers and authors. In recent years, however, academic writing has lost the cachet of being neutral, objective, and one-sided and has included interaction between readers and authors within its scope (Hyland, 2005). This development shows that academic writing not only reflects reality but also that authors can achieve an interaction with their readers. As this idea gains more popularity among researchers and in academic contexts, researchers have been giving more attention to how interaction can be achieved in academic texts. In line with this development, the concept of 'metadiscourse' (MD) has gained greater awareness.

Metadiscourse can be defined as an umbrella term used for self-reflective expressions applied to achieve an interaction with readers in order to help authors to express their ideas and to be part of the social community for which they are writing (Bayyurt et al., 2015). The term maintains that writing is not just delivering information which includes only facts, it also explicitly or implicitly includes the attitudes, personal beliefs, personalities, and assumptions of the authors, which helps authors to create an interaction with their readers (Hyland, 2005). Specifically, authors both explain the facts of information to the readers and have an opportunity to convey their personalities and opinions about the topic. Hyland (2005) divided metadiscourse into two categories, one of which was 'interactional metadiscourse' (IMD). IMD principally focuses on personal relationships involved in texts between writers and readers and the ways to increase interaction between them to indicate the stance of the writers. The interactional metafunction of metadiscourse (Halliday, 1994) refers to the implementation of language to spark interaction, allowing writers to engage with their readers and enable them to understand evaluation and feelings (Hyland, 2005).

For the present study, we adopted Hyland's (2005) IMD model because it has a wide scope. We wanted to focus on the authorial presence provided by we as self-mentions and the discourse functions signaled in texts in the field of engineering and technology since the use of first-person pronouns is known to be one of the most effective ways of manifesting authorial presence.

\section{Related Literature}

With the spread of English as the international language of the academic world, AngloAmerican academic literacy has started to interact with other academic literacies and both native and non-native writers in the academic genre have had a tendency to become the part of the interactional community, which concomitantly increases the demand for the implementation of stance (Dontcheva-Navrátilová, 2013). The concept of stance is one of the key resources of academic interaction and an extensive amount of research has been conducted in recent decades to analyse the use of stance markers in academic texts. Most of these studies have clearly shown that academic writings are personal rather than being totally impersonal, so stance has taken on a greater importance in the academic world. Thompson and Ye (1991) defined stance as the "evaluative space" which is created by authors to reflect their point of view and their perception about their messages conveyed in their texts (Akbaş \& Hardman, 2017). Stance expresses 'voice' or 'community' determined by the personality of authors and is the way in which writers inscribe their presence onto their texts (Hyland, 2005). Writeroriented features of this interaction are one of the main concerns of stance and include the ways 
in which authors can comment on the accuracy and credibility of their claims and convey the intended attitude more directly to their readers (Hyland, 2005).

Hyland (2005) suggested that stance has three components: evidentiality, affect and presence. Evidentiality deals with the commitment of writers to the reliability of their texts and their impact on the readers; effect refers to the personal attitudes and includes the beliefs and emotions of the writers; and presence concerns the ways in which writers choose to show themselves in their texts. In other words, a stance can be achieved with the help of the epistemic status about what writers claim, which allows the existence of propositions to be seen explicitly and gives space for writers to create different styles (Akbaş, 2014). Moreover, the stance theory of Martin and White (2004) mostly dealt with the feelings and values developed between readers and authors since writers develop a stance for both their texts and their readers. There are four different ways, self-mention, boosters, hedges and attitude markers, to achieve stance in academic writings, but this literature review focuses on studies related to self-mention since the main focus of this study is authorial presence achieved through the first-person plural pronoun we.

Authorial presence can be defined as a device for showing a writer's voice and credibility through the use of explicit and implicit forms. Writers can demonstrate their authorial presence explicitly, with the help of personal pronouns, or less explicitly, through the implementation of passive structures (Akbaş, 2014). What determines the way of showing authorial presence is the choice of the authors. If they prefer to highlight their presence, they choose the explicit way (the use of first-person pronouns), but if they want to obscure it, they adopt the implicit way (the use of passive structures). Nonetheless, it is important to bear in mind that one of the most effective concepts of persuading readers and interacting with them is self-mention (Dueñas, 2017). Moreover, Hyland (2002) stated that the explicit use of personal pronouns helps writers to show their identities, involve themselves in the discourse community and create interaction with their readers. The importance of an explicit authorial presence concomitantly reveals some inter-related issues. Hyland (2002) pointed out that a range of social and psychological factors might determine the choices of writers to present their authorial presence. One of the most significant factors is the kind of science in which authorial presence is used. Hyland (2002) explored the relationship between authorial presence and hard and soft fields with a corpus comprising 1.3 million words in 240 RAs in eight related disciplines and found that writers from soft disciplines were four times more likely to use explicit authorial presence than those from hard disciplines. Another study conducted by Hyland (2001) can be defined as one of the most notable studies as he examined the use of personal pronouns in hard and soft fields in a corpus totaling 1.4 million words. The results clearly showed that whereas authors from the soft fields tended to use $I$ to display an authorial presence, researchers from hard fields used we. The reasons for these results can be interpreted in two different ways.

First, it is highly possible that there is a logical need to use we in multi-authored texts, and the second reason might be that single authors in hard fields chose the use of we to create communality (Akbaş \& Hardman, 2017; Pennycook, 1994). Harwood (2005) conducted research into single-authored RAs in the field of physics and interestingly the results of his study were similar to those in Hyland's (2001) study. Harwood (2005) found that even singleauthored researchers from hard fields preferred to use exclusive we to indicate their authorial presence.

Another feature inter-related with authorial presence might be disciplinary variation. McGrath (2016) studied the similarities and differences between two disciplines - anthropology and 
history - and found that authors in anthropology used more self-mentions than the writers in history. It can be stated that the difference between the two disciplines might be the result of the nature and content of the disciplines. It is natural to use more self-mentions in anthropology since researchers want to share their current personal experiences whereas authors in history mostly describe past events involving historical figures.

Akinci (2016) conducted a cross-disciplinary study with a corpus consisting of RAs written in the fields of applied linguistics and civil engineering, which were chosen as representatives of hard and soft sciences. The findings showed a significant difference between two disciplines in terms of the frequency of self-mentions. The writers in applied linguistics preferred to employ self-mentions more frequently than those in civil engineering. This finding confirmed the inferences of a previous researcher, McGrath (2016). It is therefore again possible to deduce from the results that authorial presence through self-mentions might be shaped by crossdisciplinary variation.

Additionally, in a study of dissertations, which were intentionally chosen because academic writing is closely associated with the representation of authorial presence, the whole corpus was approximately 300,000 words and the results were note-worthy. Akbaş and Hardman (2017) found that the rate of the we-oriented authorial presence was 2.4 instances per 1000 words for Turkish L1 (TL1) writers but only 1.0 instance per 1000 words for English L1 (EL1) writers. The rate of the TL1 writers was therefore nearly three times that of the EL1 writers even though the texts were single authored. From this finding, it might be presumed that the use of authorial presence might differ between groups with the aim of avoiding involvement.

Hyland (2001) stated that we-based references in single-authored texts might be the result of a desire to avoid personal involvement and to create less explicit authority. Although it is possible to find a great number of studies looking at authorial presence in general, those which analysed we-based authorial presence are relatively limited and focused predominantly on the engineering and technology discipline for identifying disciplinary practices. The present study therefore focuses on the we-based authorial presence and its different discourse functions in the field of engineering and technology.

\section{Methodology}

In the present study, we chose to use a mixed-method research approach in order to reach more detailed findings with respect to the phenomenon under investigation. We carried out both a quantitative study in order to investigate the frequency counts of the first-person plural pronoun used to manifest the authorial presence of the writers and a qualitative study to determine the different discourse functions of we-oriented authorial presence. We used these two approaches at the same time in order to reinforce through the qualitative analysis the statistical results which were obtained from the quantitative analysis.

\section{Corpus}

The study is based on an analysis of a corpus of 200 Results and Discussion sections from RAs published in the field of engineering and technology. The articles were collected at random through the freely available electronic corpus generator tool 'AntCorGen' (Anthony, 2019). The total number of words in the corpus was 271,359 . Table 1 shows the distribution of the corpus. 
Table 1 . The size of the corpus

\begin{tabular}{lllll}
\hline Discipline & $\begin{array}{l}\text { Total number } \\
\text { of Results and }\end{array}$ & $\begin{array}{l}\text { Total number } \\
\text { Discussion } \\
\text { sections }\end{array}$ & $\begin{array}{l}\text { Average number } \\
\text { of words per } \\
\text { section }\end{array}$ & $\begin{array}{l}\text { Total number } \\
\text { of word types }\end{array}$ \\
\hline $\begin{array}{l}\text { Engineering } \\
\text { and Technology }\end{array}$ & 200 & 271,359 & 1,357 & 11,988 \\
\hline
\end{tabular}

As far as the number of words in each Results and Discussion section is concerned, it seems to be relatively low, with 1,357 words in average.

\section{Overview of the research}

Both corpus-based and corpus-driven research types were intended to be applied in the present study in line with the initial research idea, but after the pilot analysis of the corpus, the main idea of the research was reshaped. Although the type of metadiscourse was interactional originally, the sub-category of IMD was limited to 'self-mention' after the data were obtained from the sample analysis. The research design of the study consisted of five stages as shown in Figure 1.

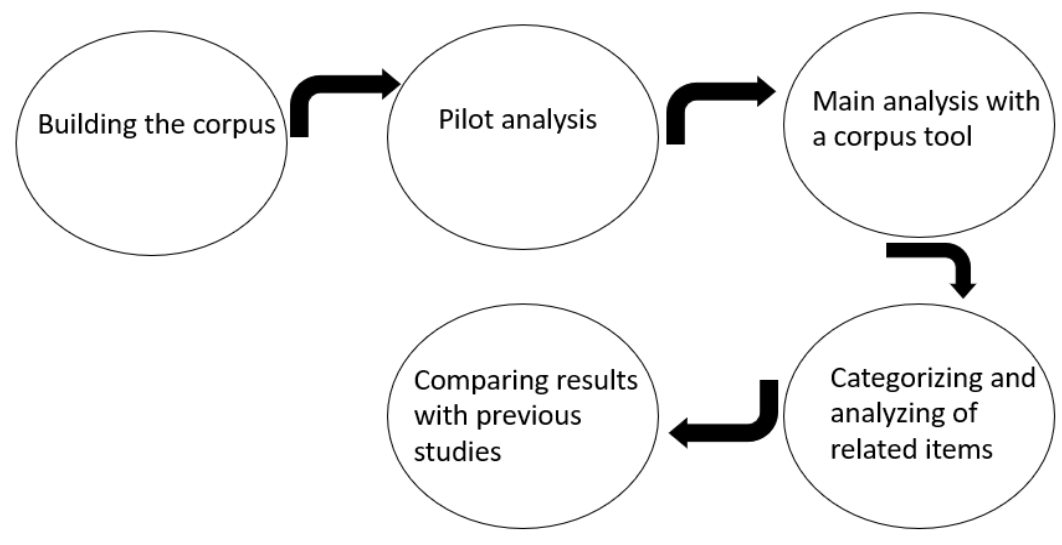

Figure 1. General view of the research procedure

In order to ensure the reliability of the results, we carried out an inter-rater reliability procedure using Cohen's kappa statistic, known to be "a robust statistic useful for either interrater or interrater reliability testing" (McHugh, 2012, p.279), between two coders. Using $10 \%$ of the cases identified in our corpus, we invited another researcher with prior experience of coding data following classifications with respect to the communicative functions of self-mentions. When the selected cases had been coded by all the raters, we calculated a Cohen's kappa statistic as a measure of categorical sorting. The results showed an almost perfect level of agreement (.881) between coders and we were able to reach a consensus over the few instances evaluated differently by the coders. This clearly made the coding scheme of the communicative functions reliable and enabled us to present more robust results with total confidence. 


\section{Analytical Framework}

Although academic writing has been seen as objective and impersonal for a long time, its old-fashioned features have started to evolve, and it has become subjective and personal. Its new principles have brought a new scope to academic writing and many researchers have demonstrated that academic writing can be made more efficient and effective with an interaction between writers and readers. Metadiscourse is a perfect term to explain and identify interaction since it refers to the expression of writers to interact with their readers. Many researchers divide metadiscourse into different groups but in this current study, Hyland's (2005) IMD model was applied as a starting point for the analysis of the sub-section of stance. We focused on the use of self-mention by the first-person plural pronoun and its discourse functions. The lists of discourse functions used in different previous studies (Akbaş \& Hardman, 2017; Dueñas, 2017; Hyland, 2002) were implemented in this study. We used AntConc (Anthony, 2020), a freeware corpus analysis tool, to analyse and concordance the target linguistic items. After completing the analysis of the authorial references, all frequencies of the lexical components were normalized to per 100 words. By this means, ten principal discourse functions of the we-based authorial presence were determined in the contextual analysis, adding to the qualitative understanding of our data. The discourse functions of authorial references throughout the Results and Discussion sections were:

(1) Stating a goal/purpose: The writers explain their purpose in carrying out the research.

(2) Explaining a procedure: The authors seek to make the procedure more understandable for their readers.

(3) Showing results/findings: The researchers clarify their findings - mostly using the verb 'find', as can be seen in example 3 below.

(4) Assessing the limitations of their research: The writers criticize themselves or the research procedure.

(5) Showing the personal beliefs/ideas of the writers about the study: The authors communicate with their readers by explaining their personal beliefs.

(6) Assessing the strength of their research: The researchers try to show the strong perspective of their study.

(7) Describing themselves: The writers introduce themselves to their potential readers in order to create an invisible connection.

(8) Making a claim/prediction: The authors show their hesitation about a claim or prediction.

(9) Making suggestions: The researchers give advice to their readers for future research.

(10) Stating a hypothesis, an expectation, or a wish: The writers clearly state their expectation from for the results.

The following examples clearly show the discourse functions of the 'we-based' authorial presence presented above.

(1) In particular, we wanted to answer four questions: 1) What is the minimum length of time and minimum IPTG concentration? [...] (Function 1)

(2) We adopt a coarse-grained approach and study the network-level [...] (Function 2)

(3) Additionally, we found no significant effects between the source of [...] (Function 3)

(4) We were not able to calculate the invariance either because of [...] (Function 4)

(5) We believe that these proposals can help ensure that any action [...] (Function 5)

(6) Also, we are able to derive global properties of the network, such as its loopiness [...] (Function 6) 
(7) We are activists, educators, technologists, and community organizers interested in new ways [...] (Function 7)

(8) We estimate that this value can be further increased to reach [...] (Function 8)

(9) Therefore, we should not only consider the haulage costs of the three routes [...] (Function 9)

(10) We expect that resolution of the mobile phone microscope will be worse than the Rayleigh criterion [...] (Function 10)

Although it is possible to find many other discourse functions in previous studies, only the ten functions described above will be analysed in the present study. In short, the RAs were used to analyse the we-oriented authorial presence and its discourse functions. We shall discuss the results in the next section.

\section{Results and Discussion}

\section{Overview of the results}

The overall findings showed that some authors chose not to employ the first-person plural pronoun we in their Results and Discussion sections. To be more specific, whereas only $89(45 \%)$ of the Results and Discussion sections included first-person plural pronouns, 111 $(55 \%)$ of them did not contain any 'we' instances at all. It can be inferred from the analysis that the writers of 111 texts downplayed their joint presence by not employing explicit references to their authorial selves. Regarding 89 texts, we found 1322 instances of we through which the authors promoted their presence and accomplished a range of authorial roles. In the current study, we also employed a contextual analysis of these authorial references in our corpus in order to reach a qualitative understanding of the self-mentions made by the authors in the Results and Discussion sections of RAs. We shall discuss the discourse functions accomplished through the authorial reference 'we' $(n=1322)$ in the following sections.

\section{Discourse functions of the we-based authorial presence}

The rhetorical functions of authorial references are perfect ways to gain approval for a writer's work (Hyland, 2004). Furthermore, authorial presence could have rhetorical importance since it indicates the ways of commitment by which authors seek to show their personal beliefs. Furthermore, it can be stated that texts which include authorial presence are easier for readers to understand and interpret since authorial presence is a sub-section of the IMD which enables interaction with the readers. Through the contextual and functional analysis of self-mentions in our data, we found a range of rhetorical functions of we-based authorial references. In line with this, in this section, we shall elaborate on the classification of the discourse functions of the first-person plural pronouns in our corpus. Table 2 shows the five verbs most frequently used with the first-person plural pronoun along with some examples. The reason why we considered the accompanying verbs following the authorial 'we' reference is linked to Fløttum's (2012) suggestion of analysing personal pronouns in combination with the verbs accompanying them in order to find out how different roles can appear.

Table 2. The most frequent five verbs collocated with "we"

\begin{tabular}{lll}
\hline Verbs & $\boldsymbol{f}$ & Examples from the corpus \\
\hline find & 91 & We find similar, but less marked behavior in Devon, owing to the $[\ldots]$ \\
have & 88 & Moreover, we have no field data for the target species and $[\ldots]$ \\
use & 62 & Therefore, we use the linked model for our analysis proper. \\
show & 52 & We show here that RBT overcomes these three problems.
\end{tabular}


We observed no clear link between pseudogene carriage and source (human and veterinary isolates).

As can be clearly seen in Table 2, the first-person plural pronoun was used most frequently in the corpus with the verbs find, have, use, show and observe. Regarding the verbs accompanying authorial references, Akbaş (2014) suggested that the authorial role is distinct even if it seems to appear within a similar linguistic environment, such as the authorial references $I$ and we collocating with the verb 'summarize' signaling a discoursal activity and the verb 'think' presenting a more personalized opinion on the topic. In line with this, Table 3 shows the distribution of authorial references in the corpus by their communicative discourse functions.

Table 3. Discourse functions of the we-based authorial presence in the corpus

\begin{tabular}{lll}
\hline Functions & $\boldsymbol{f}$ & $\mathbf{\%}$ \\
\hline Explaining a procedure & 723 & 54.69 \\
Showing results or findings & 403 & 30.48 \\
Stating a goal or purpose & 66 & 4.99 \\
Assessing the strength of their research & 34 & 2.57 \\
Assessing the limitations of their research & 33 & 2.50 \\
Showing the beliefs of the writers about the study. & 25 & 1.89 \\
Making suggestions & 19 & 1.44 \\
Stating a hypothesis, an expectation, or a wish & 15 & 1.13 \\
Describing themselves & 2 & 0.15 \\
Making a claim or prediction & 2 & 0.15 \\
Total & $\mathbf{1 3 2 2}$ & $\mathbf{1 0 0}$ \\
\hline
\end{tabular}

Table 3 shows that the we-based authorial presence in the corpus was mostly used to explain a procedure and to show the results and findings of a study, whereas more argumentative and interactional functions, such as stating a hypothesis, making suggestions and making a claim, were mainly presented in a less explicit way. This distribution might have two different reasons. First, writers might frequently use we to explain a procedure because the RAs were in the field of hard science and in this field there are more complicated procedures compared with soft science. Furthermore, hard science includes more experiments which need to be explained to make the procedure and the research clearer and more understandable for the readers (Helmenstine, 2021). The second reason could be the desire to avoid interacting with the readers and showing their attitudes to their audiences since less-used functions such as making suggestions and describing themselves enable greater interaction with readers and show writers' attitudes compared with the most frequent functions.

\section{Explaining a procedure (54.69\%)}

The ability to plan and implement an appropriate research methodology is a sign of a researcher's ability to integrate and apply professional skills in academic writing, which is seen as a significant requirement in academic writing. It also reflects a low degree of personal exposure and helps readers to focus on the procedures (Hyland, 2002). Explaining a procedure in an explicit way also enables readers to focus on the procedures easily compared with an implicit explanation. Furthermore, the use of an exclusive we to explain procedures was also found to be the most common function by Hyland (2002). Similarly, the present study produced similar results to those of Dueñas (2017). As can be seen from the three examples below, the discourse functions of a we-oriented authorial presence make the procedures more organized and understandable. 
(11) Next, we adapt and apply the event study methodology to our data.

(12) As a comparative baseline, we deleted $15 \%$ of flow from the OD matrix at random and performed ITA.

(13) We applied the Okada filters with different window lengths, three, five and seven frames $[\ldots]$.

Doğan-Uçar and Akbaş (2022) found that explaining a procedure is a relatively most employed communicative function in RA abstracts in the hard sciences. As already explained, although the examples were collected from the Results and Discussion sections of the selected RAs, writers chose to explain the procedures of their studies in a detailed way at the end of the text in order to consolidate the study and the findings. Moreover, explaining procedures in the Results and Discussion sections might have a positive correlation with the academic identity of the writers since the more understandable the study is for the readers, the more powerful the academic identity which the writers present for their readers.

\section{Showing results/findings (30.48\%)}

It is not surprising to find that showing results and findings was one the most frequent discourse functions of the we-oriented authorial presence in the Results and Discussion sections. However, Hyland (2002) stated that using the first-person plural pronoun to show results is the most self-assertive and face-threatening use of a we-oriented authorial presence since it is bald to state that 'we found' and this might not be a method of presentation chosen by many authors. As an example, Dueñas (2017) found that showing an authorial presence when presenting results and findings was used less often than was the case in the present study. There can be two possible reasons for this difference. First, Dueñas (2017) collected articles from soft science and there might therefore have been fewer experimental results to show. A second reason is clearly the choice of the writers to avoid manifesting their authorial presence. Although the use of rhetorical functions depends on a writer's choice, showing results and findings is an excellent opportunity for writers to show their command of the topic, their attitude, their efforts, and their commitment to an interpretation. The following examples from the RAs illustrate how writers showed their claims and linked themselves to their ideas:

(14) We found equal movement volumes in both directions - both suburbanites moving [...]

(15) Moreover, we have observed that the stimulation behavior seems to be equivalent to that that would be obtained using regular LF pulses.

(16) We therefore conclude that neurons that show a high degree of invariance could be useful to extract signal $[\ldots]$

These authors chose to show the results of their study with active structures rather than using the passive voice, which was a signal that they were emphasizing their authorial presence and efforts.

\section{Stating a goal/purpose (4.99\%)}

Writers used the first-person plural pronoun to show their discoursal purpose and to signal their intentions. Furthermore, stating a goal or purpose enables writers to show the systemic structure and direction of the research (Hyland, 2002). Although many writers choose to hide their authorial presence and state their goal implicitly in the introduction section, as was found by Harwood (2005), it is quite interesting to find this explicit discoursal function being used frequently in the Results and Discussion sections in the corpus. The writers might have 
wanted to create more coherent Results and Discussion sections by stating their goals through authorial presence since hard science is more complicated than soft science.

(17) We will discuss in more detail below [that] our study replicates, but also has several advantages over, previous degradations performed in the temporal or spectral domain alone.

(18) In particular, we aim to characterize the phenomenon of neighborhood partitioning globally over entire cities.

(19) Finally, we also wanted to explore to what extent is the invariance of signal in noise dependent on the exact statistics of the signal and noise stimuli.

As these examples show, the writers chose different words to state their goals. The writer(s) of example 18 chose to use 'aim', whereas the writer(s) of example 19 chose 'want', which enables a more interactive mood with the readers.

\section{Assessing the strength of their research (2.57\%)}

Writers integrate the strength of their research into their studies in order to highlight their efforts and their contribution and to represent their study as valid; they might also want an opportunity to become members of their specific disciplinary community (Dueñas, 2017). Similarly, showing the strong points of the research can increase the credibility and accountability of the writers for the readers. The following three examples show different choices made by authors to show the strength of their research.

(20) Finally, with all these values, we are able to characterize the fluorescent protein dynamics by estimating the fluorescent reporter expression rate (Fig 5E).

(21) Although still far from a complex architecture that we could identify with a 'computer', our method shows enormous potential to achieve such a goal.

(22) By carefully orienting our electrode angle, we were able to sample NCM along its entire dorsal to ventral extent.

These writers similarly chose active structures to demonstrate the strength of their research, which can be associated either with the desire to attract appreciation or with simply wanting to increase the credibility of their research. However, they avoided concealing their existence for whatever reason and emphasized their own strong academic presence alongside the study. For instance, example 20 clearly illustrates that the writers highlighted their ability by choosing 'be able to'.

\section{Assessing the limitations of their research (2.50\%)}

Writers of the RAs in the field of engineering and technology included both positive and negative assessments of their own research in the Results and Discussion sections of the RAs. They can anticipate decreasing the critiques of the readers and they contribute to saving face by showing the limitations of their research (Brown \& Levinson, 1987; Myers, 1989). Furthermore, writers might assess the limitations of their research in order not to take responsibility for possible errors in the study.

(23) [...] We do not have a concrete answer of how it happens and how to correct it.

(24) We do note that the model only considers exposure to fire, and we have not considered the size of the fire or the extent of the interface exposed to the fire. 
(25) One of the things we've never done before but we'd like to do, is to have a look at some of the health benefits associated particularly [...].

These authors explicitly show not only the strength of their research but also its limitations, which can be strongly associated with the aim of creating transparency for their readers. In line with this, example 25 shows that the writers explicitly addressed their limitations and emphasized it through the use of 'never'.

\section{Showing the beliefs of the writers about the study (1.59\%)}

This type of function may be the most appropriate function for interacting with potential readers since writers explicitly show their opinions in it. Showing the beliefs of the writers is also another way to increase the credibility and validity of academic writing since the writers are (or are seeking to be) the authorities in their academic writings. Furthermore, writers have an opportunity to involve their readers in the interaction, to become part of the relevant social community and to create personal and subjective academic writing rather than an impersonal presentation through expressing their opinions.

(26) Despite this, we believe these results provide the first instance [...].

(27) We yield that Kalantaris's bound Theorem (12) is best, and particularly Table 1 supports the fact that $[\ldots]$

(28) We would advocate that the nanorecorder's time $[\ldots]$

From these examples, it can be concluded that the writers wanted to indicate their beliefs or opinions about their study directly without hesitations or hedges, which can be a sign of selfconfidence in their study.

\section{Making suggestions (1.44\%)}

Although making suggestions was found to be a less frequent rhetorical function of the we-based authorial presence, it can be described as one of the most crucial ways to interact with the readers since the writers directly address their readers. It can also help researchers who want to study the same issue in their future studies since it gives them the opportunity to change and reorganize their ideas.

(29) We suggest a robotic liquid handling platform to produce blends to yield a pre-defined color, $\mathrm{pH}$ and density from a set of starting materials.

(30) $[\ldots]$ we should reject the hypothesis that the empirical distribution and corresponding power law $[\ldots]$.

(31) We would recommend that: planning processes are strengthened by establishing clearer guidelines $[\ldots]$

Writers might wish to contribute to future studies by giving advice to their readers and to have an interaction with them by reducing the earnestness of their academic writing.

\section{Stating a hypothesis, an expectation, or a wish (1.13\%)}

Despite the fact that it was among the less frequent discourse functions of we-based authorial presence just like 'giving suggestions', this function provides a good opportunity for writers to interact with their readers by stating their expectations, wishes or hypotheses, which are their predictions of the possible results. Furthermore, it can encourage other researchers who read the studies to state their own hypotheses or expectations explicitly. 
(32) We expected that this movement would occur prior to the point at which the greatest deviation in road position occurred.

(33) We hypothesize that, in contrast, many women (and men) in economically undeveloped countries do not have the luxury [...]

(34) We thus hope that this project will contribute to the democratization of science, technology, and innovation in education.

As these three examples show, stating a hypothesis, an expectation or a wish enables writers to interact with their readers, manifest their authorial presence, and show their ideas about the study.

\section{Describing themselves $(0.15 \%)$}

Writers in the corpus of the present study chose to use this function just twice since they might have thought that describing themselves could threaten the objectivity of the study or be irrelevant in the field of engineering and technology. As discussed earlier, however, studies have shown that academic writing has started to change its scope and to offer a place for personal ideas, which can actually make it more successful. It is therefore important for writers to include themselves in their academic writing.

(35) We are outside of the situation, however; it is highly potential [...]

(36) We are activists, educators, technologists, and community organizers interested [...]

As can be seen in these two examples, describing themselves rhetorically enabled the writers to interact with the readers and readers can find some common ground with the writers so that academic writings can be more efficient and interactive.

\section{Making a claim/prediction (0.15\%)}

Making a claim or prediction was the other least-used function for the authorial we found in the present study because writers might be afraid of making a claim or prediction in an experimental study. Moreover, because it was the Results and Discussion section of RAs which were analysed, it could be expected that we would not find many claims or predictions. If we had analysed the Introduction or Abstract sections, the likelihood of finding claims or predictions would have been higher.

(37) We estimate that this value can be further increased to reach hundreds of milliwatts by optimizing $[\ldots]$

(38) $[\ldots]$ we assert that the results presented here are accurate projections of the cost and effect $[\ldots]$

\section{Concluding remarks and implications}

Self-mention has a central pragmatic role in academic discourse since it contributes both to authors' manifestation and to their rhetorical functions (Hyland, 2002). The authorial pronoun is a significant means of expressing beliefs, increasing the credibility and accountability of the authors, helping them to become part of the social community, and enabling interaction with their readers. The purpose of the present study was to investigate the use and rhetorical functions of the we-oriented authorial presence in the Results and Discussion sections of RAs written in the field of engineering and technology. The findings have evidenced that writers used the we-based authorial presence for the following discoursal functions: (1) stating a goal or purpose, (2) explaining a procedure, (3) showing results and findings, (4) 
addressing the limitations of their research, (5) showing the personal beliefs and ideas of the writers about the study, (6) demonstrating the strength of their research, (7) describing themselves, (8) making a claim or prediction, (9) making suggestions, and (10) stating a hypothesis, an expectation or a wish. The most frequent discourse function was found to be explaining a procedure, with 723 occurrences $(54.69 \%)$ and the least-used functions were describing themselves and making a claim or prediction, with two occurrences each $(0.15 \%)$.

Based on the results, it can be stated that the most frequent function was explaining a procedure because the selected RAs were in the field of engineering and technology and included complicated experimental procedures which needed to be explained to make the studies more comprehensible and understandable for the readers. The reason for the less frequent use of describing themselves and making a claim or prediction might have been the writers' desire to avoiding manifesting their authorial presence and to protect their face and authority by not making a claim or prediction. In line with these results, it can be stated that the writers in the present study preferred to use the less argumentative and interactional discourse functions of we.

The ways which writers choose to report their study, manifest their authorial presence and express their ideas depend on different social and psychological factors such as traditions, writers' background and personality, so one of the possible reasons for the variance in the frequency of rhetorical functions might also have been one of these aspects (Hyland, 2002). Furthermore, the findings of the study are similar to those of Hyland (2002) and Dueñas (2017), who also found that explaining procedure was the most frequently used function. Although Hyland (2002) included RAs from both hard and soft science in his study and Dueñas (2017) analysed RAs in the field of soft science and the present study chose articles only from hard science, it was interesting to see the similarity of the results. This similarity enables us to assert that writers from different disciplines have a tendency to use similar discourse functions of the we-based authorial presence in their studies. Even so, it is important not to overgeneralize the results of the present study since it has several limitations. First, because it was a small-scale corpus project exploring self-mentions in the Results and Discussion sections of RAs in a specific field, it is difficult to generalize the results to have a bigger picture of the phenomenon under investigation for the discipline. The scope of the study could therefore be expanded by compiling a larger corpus and a cross-sectional perspective could be adopted in order to identify section-specific functions of self-mentions in RAs. Another limitation could be related to the fact that the study adopted a corpus-based approach and therefore might not have provided as much detailed findings as would be provided by a corpus-driven approach. Further studies could therefore focus on designing a corpus-driven study to explore authorial presence in expert writing in the discipline and focus on other ways of signalling explicit and implicit authorial presence such as phrase frames, inanimate objects and passive constructions.

As highlighted in the literature, academic writing has long been believed to be objective and impersonal, so authors could generally prefer to downplay their roles and avoid expressing their personal involvement in their academic texts. However, academic conventions can differ from one established discipline to another, or even for the interdisciplinary ones. We can therefore offer some practical implications. The first step that needs to be done is to help authors to understand that academic writing is a very specific literary form in which interactional and interactive items could make the texts more communicative. The next practical implication could be raising the awareness of researchers in particular disciplines about the rhetorical functions and the importance of an authorial presence in their fields in order to encourage them to benefit from including their authorial presence in their texts. EAP practitioners could focus 
on teaching the different discourse functions of authorial references and introducing IMD for creating successful academic communication with the intended audience. In this regard, practitioners can always benefit from the findings of previous studies as well as the current research for teaching the discourse functions of such items for establishing interpersonal communication and show different texts with and without IMD to emphasize their significance in academic writing. After the presentation and introduction of the notions, practitioners might introduce at least two texts in their classes, one which includes IMD items whereas the other does not and ask students to identify and discuss the functions of specific metadiscourse markers. Subsequently, EAP practitioners could prepare some hands-on activities with smallscale corpus study to enable students to become aware of authentic examples of authorial presence in their particular fields. Finally, practitioners could provide some explicit instruction about effective strategies and options for increasing the use of authorial presence. All in all, when students gain a mastery and understanding of the importance and functions of authorial references, they are more likely to exploit them in their own academic texts.

\section{References}

Akinci, S. (2016). A cross-disciplinary study of stance markers in research articles written by students and experts. Graduate Theses and Dissertations. 15144. https://lib.dr.iastate.edu/etd/15144

Akbaş, E. (2014). Commitment-detachment and authorial presence in postgraduate academic writing: A comparative study of Turkish native speakers, Turkish speakers of English and English native speakers (Doctoral dissertation). Retrieved from http://etheses.whiterose.ac.uk/7083/

Akbaş, E., \& Hardman, J. (2017). An exploratory study on authorial (in)visibility across postgraduate academic writing: Dilemma of developing a personal and/or impersonal authorial self. In C. Hatipoglu, E. Akbas, \& Y. Bayyurt (Eds.), Metadiscourse in written genres: Uncovering textual and interactional aspects of texts (pp. 139-174). Bern, Switzerland: Peter Lang.

Anthony, L. (2019). AntCorGen (Version 1.1.2) [Computer Software]. Tokyo, Japan: Waseda University. Available from https://www.laurenceanthony.net/software

Anthony, L. (2020). AntConc (Version 3.5.9) [Computer Software]. Tokyo, Japan: Waseda University. https://www.laurenceanthony.net/software

Bayyurt, Y., Çandarl1, D. \& Mart1, L. (2015). Authorial presence in L1 and L2 novice academic writing: a cross-linguistic and cross-cultural perspective. Journal of English for Academic Purposes, 20, 192-202.

Brown, P. \& Levinson, S.C. (1987). Politeness: Some universals in language use. Cambridge: Cambridge University Press.

Doğan-Uçar, A. \& Akbaş, E. (2022). A corpus-driven cross-disciplinary study of inclusive and exclusive we in research article abstracts. LEARN Journal: Language Education and Acquisition Research Network, 15(1), 180-204.

Dontcheva-Navrátilová, O. (2013). Authorial presence in academic discourse: Functions of author-reference pronouns. Linguistica Pragensia, 23(1), 9-30.

Dueñas, M. (2017). 'I/we focus on': a cross-cultural analysis of self-mentions in business management research articles. International Journal of Applied Linguistics, 20(1), 5072.

Fløttum, K. (2012). Variation of stance and voice across cultures. In K. Hyland \& C. SanchoGuinda (eds), Stance and voice in written academic genres (pp.218-232). Basingstoke: Palgrave Macmillan.

Halliday, M. (1994). An Introduction to Functional Grammar. London: Edward Arnold. 
Harwood, N. (2005). 'We Do Not Seem to Have a Theory ... The Theory I Present Here Attempts to Fill This Gap': Inclusive and Exclusive Pronouns in Academic Writing. Applied Linguistics, 26(3), 343-375.

Helmenstine, A.M. (2021). What is the difference between hard and soft science? Retrieved on 19 April 2021, from https://www.thoughtco.com/hard-vs-soft-science-3975989

Hyland, K. (2001). Humble servants of the discipline? Self-mention in research articles. English for Specific Purposes, 20(3), 207-226.

Hyland, K. (2002). Authority and invisibility: authorial identity in academic writing. Journal of Pragmatics, 34(8), 1091-1112.

Hyland, K. (2004). Disciplinary discourses: Social interactions. Ann Arbor: University of Michigan Press.

Hyland, K. (2005). Stance and engagement: a model of interaction in academic discourse. Discourse Studies, 7(2), 173-192.

Martin, J. \& White, P. (2004). The language of evaluation: appraisal in English. London: Palgrave Macmillan.

McGrath, L. (2016). Self-mentions in anthropology and history research articles: Variation between and within disciplines. Journal of English for Academic Purposes, 21, 86-98.

McHugh, M.L. (2012). Interrater reliability: the kappa statistic. Biochemia Medica, 22(3), 276282.

Myers, G. (1989). The pragmatics of politeness in scientific articles. Applied Linguistics, 10(1), $1-35$.

Pennycook, A. (1994). The politics of pronouns. ELT Journal, 48(2), 173-178.

Thompson, G. \& Ye, Y. (1991). Evaluation in the reporting verbs used in academic papers. Applied Linguistics, 12(4), 365-82. 